\title{
Vitamin D and Sex Differences in COVID-19
}

\author{
Maria Teresa Pagano ${ }^{\dagger}$, Daniela Peruzzu ${ }^{\dagger}$, Anna Ruggieri, Elena Ortona ${ }^{*}$ \\ and Maria Cristina Gagliardi
}

Center for Gender Specific Medicine, Istituto Superiore di Sanità (ISS), Rome, Italy

Keywords: coronavirus disease 2019 , vitamin D, estrogen, inflammation, sex/gender differences

\section{INTRODUCTION}

OPEN ACCESS

Edited by:

Alexandra Kautzky-Willer,

Medical University of Vienna, Austria

Reviewed by:

Deborah Clegg,

Cedars Sinai Medical Center

United States

Michael Leutner,

Medical University of Vienna, Austria

*Correspondence:

Elena Ortona

elena.ortona@iss.it

${ }^{\dagger}$ These authors share first authorship

Specialty section:

This article was submitted to

Translational Endocrinology,

a section of the journal

Frontiers in Endocrinology

Received: 30 May 2020 Accepted: 14 September 2020 Published: 30 September 2020

Citation:

Pagano MT, Peruzzu D, Ruggieri A,

Ortona E and Gagliardi MC (2020)

Vitamin $D$ and Sex

Differences in COVID-19.

Front. Endocrinol. 11:567824.

doi: 10.3389/fendo.2020.567824
Hypovitaminosis D is implicated in various inflammatory, infectious and autoimmune diseases and recent lines of evidence suggest that it may represent a risk factor also for the ongoing epidemic of coronavirus disease 2019 (COVID-19) (1-3). In fact, the outcome of COVID-19 appears to be influenced by vitamin $\mathrm{D}$ status of populations $(4,5)$.

Several studies have clearly shown that $1,25(\mathrm{OH}) 2$ vitamin $\mathrm{D}(3)$ (Vitamin $\mathrm{D} 3$, the active metabolite of vitamin D), besides its classical function in calcium dependent bone homeostasis, is actively involved in the regulation of innate and adaptive immune responses (6). In particular, it plays a key role in the control of the cytokine storm, i.e., the sudden acute increase in circulating levels of different pro-inflammatory cytokines, induced in several inflammatory conditions and also in COVID-19 (7). This activity of Vitamin D3 is carried out by inhibiting the production of the proinflammatory cytokines such as tumor necrosis factor- $\alpha$ (TNF- $\alpha$ ) and interferon- $\gamma$ (IFN- $\gamma$ ) but, also, by increasing the expression of the anti-inflammatory cytokine interleukin-10 (IL-10). Moreover, Vitamin D3 enhances the production of antimicrobial peptides such as human cathelicidin, LL-37 and defensins in several infections (8). A further important feature of Vitamin D3 is its capacity to reduce the risk of viral infections maintaining the integrity of the epithelium by the upregulation of genes which encode proteins required for tight, gap and adherens junctions (6). Further studies will be necessary to clarify whether all these anti-microbial effects could also occur against SARS-CoV-2, assigning to Vitamin D3 a protective role against COVID-19. Notably, Vitamin D3 enhances the expression of human angiotensin-converting enzyme 2 (ACE2), the functional receptor for SARS-CoV-2 $(9,10)$. ACE2 plays a protective role in acute respiratory distress syndrome and higher levels of ACE2 seem to be associated with better outcomes for lung diseases and, in particular, for COVID-19 (11-13).

Based on these considerations, in COVID-19 the inter-individual variability in circulating levels of 25-hydroxyvitamin $\mathrm{D}(25(\mathrm{OH}) \mathrm{D})$, the biomarker of vitamin $\mathrm{D}$ status could be involved in the different severity of pulmonary inflammation and viral pathogenicity among individuals (14). Supporting the important protective role of Vitamin D3 in COVID-19 outbreak, negative correlations between mean levels of Vitamin D3 of European countries and the number of COVID-19 cases were observed $(1,13)$. Moreover, the lethality rate increased with age and with chronic disease comorbidity, both of which are associated with decreased vitamin D3 levels (15). 


\section{COVID-19 AND SEX DIFFERENCES}

To note, epidemiological data indicate that COVID-19 has a significantly higher lethality in men than in women (ratios up to $3: 1$ ), suggesting the presence of sex-dependent biological factors underlying these differences in disease outcome $(16,17)$. It is known that, in general, innate and acquired immune responses are more intense in females than in males (18). This can provide women with a more effective defense to fight new and infective pathogens, favoring viral clearance. Another significant explanation for sex differences in COVID-19 lethality is the sex-dependent modulation of cellular receptors and co-receptors used by SARS-CoV-2 to enter human host cells. In particular, ACE2 is encoded on X-chromosome, in sites commonly escaping the inactivation of one $\mathrm{X}$-chromosome in mammalian XX cells (XCI), and could therefore be overexpressed in women (19). Moreover, estrogen induces an increase of ACE2 expression that, as reported above, could play a protective role in acute respiratory distress $(11,20)$, whereas androgen can increase the expression and activation of transmembrane serine-protease 2, (TMPRSS2), that facilitates virus-cell membrane fusion, thus favoring the infection (21).

Moreover, a large number of COVID-19 patients exhibit severe cardiovascular damage and those with pre-existing cardiovascular diseases appear to have an increased risk of death (22). To note, estrogen has known protective effects on the cardiovascular system mediated by estrogen receptors, resulting in the activation of endothelial nitric oxide synthase. Moreover, estrogen modulates serum lipoprotein and triglyceride levels and influences the expression of coagulant and fibrinolytic proteins. These estrogen-mediated actions could represent a further reason for the sex-specific differences in the outcome of COVID-19 $(23,24)$.

\section{COVID-19 AND SEX DIFFERENCES: A ROLE FOR VITAMIN D3}

A further interesting point is represented by the potential differences in serum level of $25(\mathrm{OH}) \mathrm{D}$ among men and women. Sanghera and co-workers (15) observed a significantly reduced level of 25(OH)D in both men and women with obesity that represents a further important risk factor for COVID-19. In this study, 25(OH)D level remains consistently lower in obese men than in obese women (15). On the contrary, in another study, Mucogiuri and co-workers (25) stratifying the sample population according to sex and body mass index (BMI), found that $25(\mathrm{OH}) \mathrm{D}$ concentrations were significantly higher in males compared to females in all BMI classes and decreased along with the increase of BMI values. Although these contrasting data seem to not assign to $25(\mathrm{OH}) \mathrm{D}$ a clear role in determining sex differences in obese COVID-19 patients, we think that attention could be paid to 25(OH)D levels in the context of this comorbidity.

Interestingly, sex differences have been observed in the immunomodulatory and anti-inflammatory effects of Vitamin D3 in some autoimmune diseases. In particular, a study of Correale and co-workers (26) showed that Vitamin D3 induces a stronger inhibition of the production of pro-inflammatory cytokines and a higher increase of anti-inflammatory cytokines in lymphocytes from multiple sclerosis female patients in comparison to those from male patients. Interestingly, Spanier and co-workers (27) suggested that Vitamin D3 acts in an estrogen-dependent manner in controlling $\mathrm{T}$ regulatory cell differentiation. Moreover, estrogen seems to increase the expression of the nuclear vitamin D receptor (VDR) gene in CD4+ T cells (28) and to decrease the expression of CYP24A1, the cytochrome P450 component of the 25-hydroxyvitamin D(3)-24hydroxylase enzyme which inactivates Vitamin D3. In turn, Vitamin D3 exerts tissue-specific effects on peripheral estrogen metabolism (29). Hence, the sex-related immunomodulatory effects of Vitamin D3 suggest that it is possible to speculate that also in COVID-19, Vitamin D3 could play a role in the outcome and lethality.

\section{CONCLUSIONS}

In conclusion, the outcome of COVID-19 appears to be influenced by the interaction among genetic, hormonal and environmental factors. The low levels of $25(\mathrm{OH}) \mathrm{D}$ could represent a risk factor for development of disease. In particular, it is tempting to hypothesize that the synergy between Vitamin D3 and estrogen could affect the sex differences in the outcome of patients with COVID-19. However, further studies will be mandatory in order to investigate the efficacy of Vitamin D3 supplements, in combination or not with estrogen agonists, as a valid adjuvant for prevention and/or treatment of this severe infectious disease.

\section{AUTHOR CONTRIBUTIONS}

MP and DP: study conception and design, and manuscript drafting. AR: critical revision. EO and MG: study conception and design, and critical revision. All authors contributed to the article and approved the submitted version.

\section{ACKNOWLEDGMENTS}

We thank Simona Anticoli, Maria Bellenghi, Camilla Cittadini, Katia Fecchi, Elisabetta Iessi, and Giada Pontecorvi for their precious support and constructive discussions. 


\section{REFERENCES}

1. Grant WB, Lahore H, McDonnell SL, Baggerly CA, French CB, Aliano JL, et al. Evidence that Vitamin D Supplementation Could Reduce Risk of Influenza and COVID-19 Infections and Deaths. Nutrients (2020) 12 (4):988. doi: 10.3390/nu12040988

2. Rhodes JM, Subramanian S, Laird E, Griffin G, Kenny RA. Perspective: Vitamin D deficiency and COVID-19 severity - plausibly linked by latitude, ethnicity, impacts on cytokines, ACE2 and thrombosis. J Internal Med (2020) 1-19. doi: 10.1111 /joim.13149

3. Hadizadeh F. Supplementation with vitamin D in the COVID-19 pandemic? Nutr Rev (2020) nuaa081. doi: 10.1093/nutrit/nuaa081

4. Mitchell F. Vitamin-D and COVID-19: do deficient risk a poorer outcome? Lancet Diabetes Endocrinol (2020) 8(7):570. doi: 10.1016/S2213-8587(20)30183-2

5. D'Avolio A, Avataneo V, Manca A, Cusato J, De Nicolò A, Lucchini R, et al. 25-Hydroxyvitamin D Concentrations Are Lower in Patients with Positive PCR for SARS-CoV-2. Nutrients (2020) 12(5):E1359. doi: 10.3390/ nu12051359

6. Schwalfenberg GK. A review of the critical role of vitamin D in the functioning of the immune system and the clinical implications of vitamin D deficiency. Mol Nutr Food Res (2011) 55(1):96-108. doi: 10.1002/ mnfr.201000174

7. Sinha P, Matthay MA, Calfee CS. Is a "Cytokine Storm" Relevant to COVID-19? JAMA Intern Med (2020) 1152-54. doi: 10.1001/jamainternmed.2020.3313

8. Laaksi I. Vitamin D and respiratory infection in adults. Proc Nutr Soc (2012) 71(1):90-7. doi: 10.1017/S0029665111003351

9. Kumar D, Gupta P, Banerjee D. Letter: does vitamin D have a potential role against COVID- 19? Aliment Pharmacol Ther (2020) 52(2):409-11. doi: 10.1111/apt.15817

10. Xu J, Yang J, Chen J, Luo Q, Zhang Q, Zhang H. Vitamin D alleviates lipopolysaccharide-induced acute lung injury via regulation of the renin -angiotensin system. Mol Med Rep (2017) 16(5):7432-8. doi: 10.3892/ mmr.2017.7546

11. Gagliardi MC, Tieri P, Ortona E, Ruggieri A. ACE2 expression and sex disparity in COVID-19. Cell Death Discovery (2020) 6:37. doi: 10.1038/ s41420-020-0276-1

12. Kuba K, Imai Y, Penninger JM. Angiotensin-converting enzyme 2 in lung diseases. Curr Opin Pharmacol (2006) 6(3):271-76. doi: 10.1016/ j.coph.2006.03.001

13. Ilie PC, Stefanescu S, Smith L. The role of vitamin D in the prevention of coronavirus disease 2019 infection and mortality. Aging Clin Exp Res (2020) 32(7):1195-8. doi: 10.1007/s40520-020-01570-8

14. Carter SJ, Baranauskas MN, Fly AD. Considerations for obesity, vitamin D, and physical activity amidst the COVID-19 pandemic. Obes (Silver Spring) (2020) 28(7):1176-7. doi: 10.1002/oby.22838

15. Sanghera DK, Sapkota BR, Aston CE, Blackett PR. Vitamin D Status, Gender Differences, and Cardiometabolic Health Disparities. Ann Nutr Metab (2017) 70(2):79-87. doi: 10.1159/000458765

16. Peckham H, Gruijter N, Raine C, Peckham H, de Gruijter N, Raine C, et al. Sex-bias in COVID-19: a meta-analysis and review of sex differences in disease and immunity. Res Square (2020). doi: 10.21203/rs.3.rs-23651/v1

17. Ambrosino I, Barbagelata E, Ortona E, Ruggieri A, Massiah G, Giannico OV, et al. Gender differences in patients with COVID-19: a narrative review. Monaldi Arch Chest Dis (2020) 90(2). doi: 10.4081/monaldi.2020.1389
18. Ghosh S, Klein RS. Sex Drives Dimorphic Immune Responses to Viral Infections. J Immunol (2017) 198(5):1782-90. doi: 10.4049/jimmunol. 1601166

19. Tukiainen T, Villani AC, Yen A, Rivas MA, Marshall JL, Satija R, et al. Landscape of $\mathrm{X}$ chromosome inactivation across human tissues. Nature (2017) 550(7675):244-48. doi: 10.1038/nature24265

20. Bukowska A, Spiller L, Wolke C, Lendeckel U, Weinert S, Hoffmann J, et al. Protective regulation of the ACE2/ACE gene expression by estrogen in human atrial tissue from elderly men. Exp Biol Med (Maywood) (2017) 242(14):141223. doi: $10.1177 / 1535370217718808$

21. Pozzilli P, Lenzi A. Commentary: Testosterone, a key hormone in the context of COVID-19 pandemic. Metabolism (2020) 108:154252. doi: 10.1016/ j.metabol.2020.154252

22. Evans PC, Ed Rainger G, Mason JC, Guzik TJ, Osto E, Stamataki Z, et al. Endothelial dysfunction in COVID-19: a position paper of the ESC Working Group for Atherosclerosis and Vascular Biology, and the ESC Council of Basic Cardiovascular Science. Cardiovasc Res (2020) cvaa230. doi: 10.1093/cvr/ craa2 230

23. Mendelsohn ME. Protective effects of estrogen on the cardiovascular system. Am J Cardiol (2002) 89(12A):12E-8E. doi: 10.1016/s0002-9149(02)02405-0

24. Regitz-Zagrosek V, Oertelt-Prigione S, Seeland U, Hetzer R. Sex and gender differences in myocardial hypertrophy and heart failure. Circ J (2010) 74 (7):1265-73. doi: 10.1253/circj.cj-10-0196

25. Muscogiuri G, Barrea L, Somma CD, Laudisio D, Salzano C, Pugliese G, et al. Sex Differences of Vitamin D Status across BMI Classes: An Observational Prospective Cohort Study. Nutrients (2019) 11(12):3034. doi: 10.3390/ nu11123034

26. Correale J, Ysrraelit MC, Gaitán MII. Gender differences in 1,25 dihydroxyvitamin D3 immunomodulatory effects in multiple sclerosis patients and healthy subjects. J Immunol (2010) 185(8):4948-58. doi: 10.4049/jimmunol.1000588

27. Spanier JA, Nashold FE, Mayne CG, Nelson CD, Hayes CE. Vitamin D and estrogen synergy in Vdr-expressing CD4(+) $\mathrm{T}$ cells is essential to induce Helios(+)FoxP3(+)T cells and prevent autoimmune demyelinating disease. J Neuroimmunol (2015) 286:48-58. doi: 10.1016/j.jneuroim.2015.06.015

28. Cheema C, Grant BF, Marcus R. Effects of estrogen on circulating "free" and total 1,25- dihydroxyvitamin $\mathrm{D}$ and on the parathyroid-vitamin $\mathrm{D}$ axis in postmenopausal women. J Clin Invest (1989) 83:537-42. doi: 10.1172/ JCI113915

29. Lundqvist J, Norlin M, Wikvall K. 1 $\alpha, 25$-Dihydroxyvitamin D3 exerts tissuespecific effects on estrogen and androgen metabolism. Biochim Biophys Acta (2011) 1811(4):263-70. doi: 10.1016/j.bbalip.2011.01.004

Conflict of Interest: The authors declare that the research was conducted in the absence of any commercial or financial relationships that could be construed as a potential conflict of interest.

Copyright (c) 2020 Pagano, Peruzzu, Ruggieri, Ortona and Gagliardi. This is an open-access article distributed under the terms of the Creative Commons Attribution License (CC BY). The use, distribution or reproduction in other forums is permitted, provided the original author(s) and the copyright owner(s) are credited and that the original publication in this journal is cited, in accordance with accepted academic practice. No use, distribution or reproduction is permitted which does not comply with these terms. 